\title{
SHORT-TERM EVALUATION OF THE STEROID EPIDURAL INJECTION METHOD FOR PATIENTS WITH DEGENERATIVE LUMBAR STENOSIS
}

\author{
Pamudji Utomo1,2), R. Andhi Prijosedjati1,2), Haryo Wicaksono1,2) \\ 1)Faculty of Medicine, Universitas Sebelas Maret \\ 2)Prof. dr. R. Soeharso Orthopedic Hospital, Surakarta
}

\begin{abstract}
Background: Spinal stenosis is a narrowing of the vertebral canal that compresses spinal nerves and may cause leg pain and difficulty walking. The symptoms of degenerative lumbar stenosis commonly occur in elderly adults and can be treated conservatively with pain-relieving agents or aggressively with decompressive surgery. However, studies on the effectiveness of steroid epidural injection (EPI) on reducing pain in patients with degenerative lumbar stenosis in Indonesia are lacking. This study aimed to evaluate the short-term effect of the steroid epidural injection method on the reduction of pain and disability in patients with degenerative lumbar stenosis.

Subjects and Method: This was a cohort study conducted at Prof. Dr. R. Soeharso Orthopedi Hospital, Surakarta, Central Java, from March 2015 to January 2016. A total of 50 patients with degenerative lumbar stenosis was selected for this study. The dependent variables were pain and disability levels. The independent variable was EPI. Pain level was measured by visual analog scale (VAS). Disability level was measured by Oswestri Disability Index (ODI). The outcome data before and after the intervention (EPI) were compared by t-test.

Results: Score of VAS a month after EPI (mean=36.20) was lower than before EPI (mean $=63.20)$ and it was statistically significant $(p=0.027)$. Score of ODI a month after EPI (mean $=42.82)$ was lower than before EPI $($ mean $=54.90)$ and it was statistically significant $(\mathrm{p}=0.033)$. However, scores of both VAS and ODI began to rise three months after EPI.

Conclusion: Non-operative steroid epidural injection (EPI) is effective to reduce pain and disability among patients with degenerative lumbar stenosis in the shortterm within three months after the intervention.
\end{abstract}

Keywords: steroid epidural injection, pain, disability, degenerative lumbar stenosis.

\section{Correspondence:}

Pamudji Utomo. Faculty of Medicine, Universitas Sebelas Maret, Central Java. Email: pamudjiutomo@gmail.com. Mobile: 08122585888. 